\title{
How do we learn?
}

\section{HOW I LEARNT TO REFER}

It is, after all, one of the basic skills of general practice - the writing of a referral letter, that all-important link between primary and secondary care. You can find many sorts of referral letter, from the absolute minimum of 'Dear Doctor, please see and treat' to much longer letters, badly written and so stuffed with irrelevancies as to mask that which is important. Top of the range, of course, is a letter in which there is proper use of language; the facts - history and clinical findings, and test results - are presented concisely. A diagnosis is put forward together with a note of the referring doctor's concerns and suspicions, and the whole offers a platform on which a consultant can construct an opinion and a plan of action.

In my day, at least, such writing was not regarded as a skill to be taught. We learnt it as best we could and, once you entered general practice, it did not take long to realise that the better and more useful letter you would send, the better and more useful letter you would receive. But, as I look back, I wonder how I learnt to write a referral letter. I think it all began many years before I entered general practice.

Fast backward to myself and the other students on our firm, sitting in an overheated clinic as an unwise lunch tried to force us into post-prandial torpor. The nurse ushered in a new patient; the consultant greeted her, and read her referral letter. He passed it to us in silence; it was badly written, misspelt, syntactically awful, and utterly useless. The consultant took a deep breath, and began to take a history from an embarrassed and anxious young woman.

A few days later, while on the wards, I was reading through another patient's notes; I found the original letter of referral from the GP, which was as bad as that we had seen in the clinic. In contrast, that from the consultant was a model:

'Dear $\operatorname{Dr} X$, Thank you so much for referring this charming 26-year-old shop assistant with a 2-year history of recurrent left iliac fossa pain ...'
It was written in clear concise English; it detailed the history, the clinical findings, the differential diagnosis, the investigations, the prescriptions together with a note of the odd clinical sign which, in that consultant's experience, had supported a particular diagnosis. It was, in short, an opportunity to be a fly on the wall of a particularly well-stocked mind and thereby get an idea of the consultant's thinking. It was a letter to keep - together with others like it - for, collectively, they constituted a textbook to which one could refer again and again, a textbook flavoured with the immediacy of one's own clinical practice. Many years later, I began to do just that. But there, on that ward, I wondered angrily just why it was that such letters were the prerogative of the consultant. Why was it impossible for GPs to write in this way?

Fast forward many years to that epochal meeting of like minds, at an RCGP Examiners' meeting in Cumbria, when Robin Hull and David Haslam united in bemoaning the standard of literacy among GPs. From that came the General Practitioner Writers' Association, which morphed a few years ago into the Society of Medical Writers, organisations which have done so much to foster an interest and love of the art and craft of literature and of good writing.

I was determined, from day one in general practice, to write good referral letters, detailing - as one should - the history of the problem together with the medical history, the investigations, and differential diagnosis, and, if I had no idea what was wrong, I said so. I would write and re-write and polish these letters several times for such were, I reckoned, a professional courtesy to colleagues who, in return, would write back recognising - in their replies - the value of my own workup as they discussed their own ideas on the problem and how one should proceed. I was very much the 'new kid on the block' but it was not long before I started to receive such letters, which were really mutual discussion documents and were invaluable as learning tools - and not without the occasional surprise. I recall one older lady, whose slowly progressive mental deterioration was somehow atypical; I could not get any diagnostic clue either from her history (such as she could give) or physical examination, and all my tests were negative. I requested a domiciliary psychogeriatric consultation, and sweated blood over my referral letter. In return I got a charming letter, whose opening paragraph made me wish myself at the bottom of a very deep dark hole. It read:

\section{'Dear Dr Lasserson, Thanks so much} for asking me to see this interesting lady, and for your most helpful letter. I must say that my first impression was that she could well be hypothyroid and, indeed, her thyroid function tests confirm this ...'

I fired off an immediate reply along the lines of 'Mea maxima culpa!' and the response was one of comforting reassurance together with the comment that 'we all miss these things ...' and, of course, so we do. What made such an exchange easy was that I knew the consultant; we all knew our consultants, their strengths and their special interests, through the relationships we had slowly built up over the years through our direct referrals to them; something which, sadly, is no longer possible. As this has gone, so does it seem that there is no longer a place in our referrals for good concise English, itself another casualty of the box-ticking system; and so there is no longer room for individuality of style, for the occasional aphorism, the relevant quotation or, indeed, anything which makes a referral letter stand out as a personal document. Are we, I wonder, heading back to 'Dear Doctor, Please see and treat'?

\section{Michael Lasserson}

DOI: 10.3399/bjgp11X561447 